\title{
Evaluation the Effect of Smoking on the Thickness of Central Retinal Nerve Fiber and Ganglion Cell Layer Using OCT
}

\author{
Mohamed A El-shayeb, Mohammed T Hegazy, Ashraf H El-Habbak, Marwa A Tabl
}

\begin{abstract}
Department of Ophthalmology, Benha faculty of medicine, Banha University, Egypt.

ABSTRACT:

Purpose: to investigate the possible changes in the thickness of retinal nerve fiber layer (RNFL) and the ganglion cell layer (GCL) in

Correspondence to: moderate or heavy smokers using Optical Coherence Tomography Mohamed A El-shayeb Department of Ophthalmology Benha faculty of medicine, Banha University, Egypt.

Email: with compared to nonsmoker people. Methods: This study included 20 active chronic smokers and 20 age-matched healthy nonsmokers. After a full ophthalmological examination, Peri-papillary (RNFL) and ganglion cell layer (GCL) were measured with Spectral Domain d.mohamed.elshayeb@gmail.co $\mathrm{m}$

Received: 17 October 2019

Accepted: 25 December 2021

Optical Coherence Tomography (SD-OCT). Results: Inferior and superior and nasal quadrants of RNFL were thinner in smokers, but temporal quadrants did not show significant difference between the two groups. There were no significant differences in GCL values between the two groups. Conclusion: This study reported that the thickness of retinal nerve fiber layer thickness decreases in chronic, healthy, heavy cigarette smokers, and this thinning is related to duration of smoking, but the ganglion cell layer thickness in heavy smokers was similar to those of the healthy individuals.
\end{abstract}

Keywords: RNFL; GCL; OCT; Smoking.

\section{Introduction:}

Cigarette smoking, which was proven to be a risk factor for atherosclerotic complications in the aortic, coronary, and cerebral circulation [1], causes damage in through the metabolic and vascular effects of systemically absorbed products [2]. Tobacco smoke contains oxidizing products that yield free radicals and may cause cell damage and cell death. The ocular effects of smoking are dose-dependent risks, and 
morbidity correlates with the increase in smoking index [3].

Common eye diseases such as cataract [4], age-related macular degeneration [5], retinal venous occlusion [6], anterior ischemic optic neuropathy [7], thyroid orbitopathy [8], primary open-angle glaucoma [9] and tobacco toxic optic neuropathy were found to be related to cigarette smoking.

The peri-papillary retinal nerve fiber layer (RNFL) and ganglion cell layer complex thickness, which were proved to be thinned in glaucomatous [12] and non-glaucomatous optic neuropathies [13] and other central nervous diseases [14], can be successfully evaluated with high-definition optical coherence tomography (SD-OCT) devices

Optical Coherence Tomography (OCT) is one of the most important non-invasive, reproducible and reliable ancillary tests for diagnosis of retinal pathology. It can be used for evaluation of the peri-papillary retinal nerve fiber layer (RNFL) and macular thickness and may provide a significant tool to improve the diagnosis, prognosis, and management of systemic hypertension in clinical practice [15].

\section{The aim of the study:}

to investigate the possible changes in the thickness of retinal nerve fiber layer (RNFL) and the ganglion cell layer (GCL) in moderate or heavy smokers using Optical Coherence Tomography with compared to nonsmoker people.

\section{Subjects \&Methods:}

This retrospective cohort study was done at Benha university hospitals between May 2018 and January 2019, with the participants recruited from the outpatient clinic of ophthalmology development of Benha university hospital. It was approved by the ethical committee of the Faculty of Medicine, Benha University. Informed consents were obtained from all participants.

A total of 40 participants were enrolled in the study. The participants were classified into two groups; the active smoker group included 20 participants (40 eyes) who were healthy cigarette smokers-who smoke at least 20 cigarettes for 10 years - with no other systemic or ocular disease (group I) and the nonsmoker group consisted of 20 age matched healthy never smoking participants (40 eyes) (group II). 
We included participants whose age ranged from 35 to 45 years, spherical refraction between +2.0 and -2.0 diopters, best corrected visual acuity (BCVA) of 20/20 or better, clear media , intraocular pressure < $20 \mathrm{mmHg}$, and In group I, participants smoke at least 20 cigarettes/day for at least 10 years duration .We excluded any participant with pre-existing retinal diseases, glaucoma, previous LASIK or retinal surgery, previous eye trauma, a history of alcohol intake, any systemic disease specially diabetes mellitus (DM), uncontrolled hypertension, or a history of medication intake within the last 3 months, especially systemic vasoactive drugs.

All patients and control subjects were subjected to the following:

-History taking (age, gender, occupation, past-medical history, past-surgical history \& ocular history).

-Complete ophthalmic examination of both eyes including:

Best Corrected Visual acuity, objective refraction, intraocular pressure, slit lamp examination, motility examination, pupil reaction to light, color vision (red, green), fundus examination \& measurement of peripapillary retinal nerve fiber layer thickness
(RNFL) and Ganglion cell layer (GCL) thickness map in both groups with Spectral Domain Optical Coherence Tomography (SD-OCT): TOPCON 3D OCT-2000 device.

Peri-papillary RNFL was measured by 3 circular scans around the optic nerve in an area with a diameter of $3.4 \mathrm{~mm}$. We recorded the RNFL thicknesses at the superior, nasal, inferior, and temporal quadrants, and at each clock hour, the mean values were calculated. The RNFL thickness was differentiated from other retinal layers using edge detection algorithm.

Ganglion cell layer (GCL) thickness map was performed with SD-OCT. the central $9 \mathrm{~mm}$ circle centered on the fovea is divided into two halves: upper and lower halves with the total GCL thickness measured all over each half, The GCL thickness map was obtained from the macular map scan and calculated automatically. The central $1.5 \mathrm{~mm}$ circle centered on the macula, being devoid of ganglion cells, has no measurement.

\section{Results:}

The obtained results were tabulated \& statistically analyzed by the Statistical Package for Social Sciences, (SPSS version 20 - SPSS Inc., Chicago, IL, USA). 
The participants were classified into two groups; the active moderate or heavy smoker group included 20 eye of persons who smoke at least 20 cigarettes per day for at least 10 years with no other systemic or ocular disease (group I) and the non-smoker group consisted of 20 eyes of healthy person never smoking (group II). The mean age of the smoker group is $39 \pm 5$ years and the mean age of the non-smoker group is 40 \pm 6 years, there is no statically significant difference between two groups.The smoker group was purely males and the non-smoker group there are (11) males and (9) female as tabulated in (Table 1).

Number of cigarettes/day was ranged between (20) and (40) and the mean was (27 \pm 7 ). Duration of smoking (years) ranged between (11y) and (24y) and the mean was (17 \pm 4 years), as tabulated in (Table 2).

The mean thickness of temporal nerve fiber layer at the smoker group was $(72 \pm 17)$ and the mean thickness at the non-smoker group was $(75 \pm 13)$ and there are no significant difference as $(\mathrm{P}=0.738)$.The mean thickness of superior nerve fiber layer at the smoker group was (111 \pm 20$)$ and the mean thickness at the non-smoker group was (130 \pm 19$)$ and there are a significant difference as
$(\mathrm{P}=0.002)$.The mean thickness of nasal nerve fiber layer at the smoker group was (76 \pm 21$)$ and the mean thickness at the nonsmoker group was $(89 \pm 14)$ and there are a significant difference as $(\mathrm{P}=0.026)$.The mean thickness of inferior nerve fiber layer at the smoker group was $(105 \pm 23)$ and the mean thickness at the non-smoker group was ( $132 \pm 16)$ and there are a highly significant difference as $(\mathrm{P}<0.001)$ as tabulated in (Table 3).

The mean of the thickness of inferior quadrant of GCL at the smoker group was $(75 \pm 6)$, at the non-smoker group $(74 \pm 5)$. The mean of the thickness of superior quadrant of GCL at the smoker group was $(75 \pm 5)$, at the non-smoker group $(73 \pm 5)$ .There are no significant difference between superior or inferior GCL complex thickness as $(\mathrm{P}>0.05)$ as tabulated in (Table 4).

The obtained results showed a positive correlation between superior RNFL thickness and the age as $(r=0.32)$ and a positive correlation also between superior RNFL thickness and Number of years since started smoking as ( $r=0.078)$, but there are a negative correlation between superior RNFL thickness and Number of cigarettes/day as $(r=-.627)$ (Fig.1). 
Our results showed also a positive correlation between inferior RNFL thickness and the age as $(r=0.352)$, but there are a negative correlation between inferior RNFL thickness and Number of cigarettes/day as( $r$ $=-.673)$ (Fig.2).

Table (1): Demographic characteristics in both groups

\begin{tabular}{lcccc}
\hline & & Smokers & Non-smokers \\
$(\mathbf{n = 2 0})$ & $(\mathbf{n = 2 0 )}$ & P value \\
\hline Age (years) & Mean \pm SD & $39 \pm 5$ & $40 \pm 6$ & 0.512 \\
Sex & Males & $20(100.0)$ & $11(55.0)$ & - \\
& Females & $0(0.0)$ & $9(45.0)$ & - \\
\hline
\end{tabular}

Table (2): Number of cigarettes and duration of smoking

\begin{tabular}{ll}
\hline & Mean \pm SD \\
\hline Number of cigarettes/day & $27 \pm 7$ \\
Duration of smoking (years) & $17 \pm 4$ \\
\hline
\end{tabular}

Table (3): Thickness of nerve fiber layer in in smokers and non-smokers

\begin{tabular}{|c|c|c|c|c|}
\hline $\begin{array}{l}\text { R.N.F.L } \\
\text { Thickness }\end{array}$ & & $\begin{array}{l}\text { Smokers } \\
(\mathrm{n}=20)\end{array}$ & $\begin{array}{l}\text { Non smokers } \\
(\mathbf{n}=20)\end{array}$ & $P$ value \\
\hline Temporal & Mean \pm SD & $72 \pm 17$ & $75 \pm 13$ & 0.738 \\
\hline Superior & Mean \pm SD & $111 \pm 20$ & $130 \pm 19$ & $0.002 *$ \\
\hline Nasal & Mean \pm SD & $76 \pm 21$ & $89 \pm 14$ & $0.026^{*}$ \\
\hline Inferior & Mean \pm SD & $105 \pm 23$ & $132 \pm 16$ & $<0.001^{* *}$ \\
\hline
\end{tabular}

*significant **highly significant 
Benha medical journal vol. 39, special issue (ophthalmology), 2022

Table (4): Thickness of GCL in smokers and non-smokers

\begin{tabular}{ccccc}
\hline & & $\begin{array}{c}\text { Smokers } \\
(\mathbf{n}=\mathbf{2 0})\end{array}$ & $\begin{array}{c}\text { Non smokers } \\
(\mathbf{n}=\mathbf{2 0})\end{array}$ & P value \\
\hline Inferior & Mean \pm SD & $75 \pm 6$ & $74 \pm 5$ & 0.49 \\
Superior & Mean \pm SD & $75 \pm 5$ & $73 \pm 5$ & 0.397 \\
Total & Mean \pm SD & $75 \pm 5$ & $73 \pm 5$ & 0.471 \\
\hline
\end{tabular}

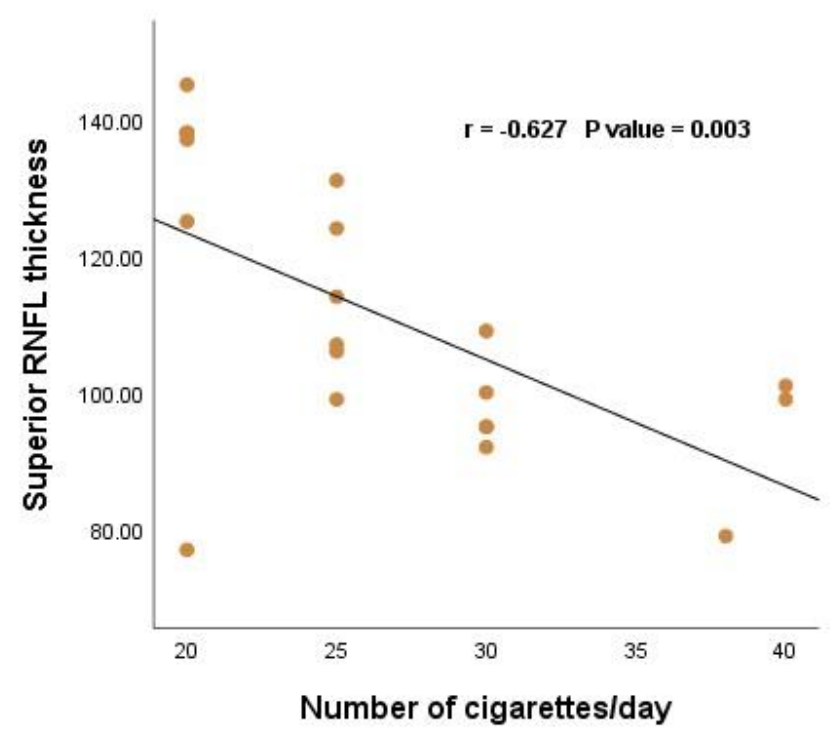

Figure 1 : Correlation between Superior RNFL thickness and Number of cigarettes/day .

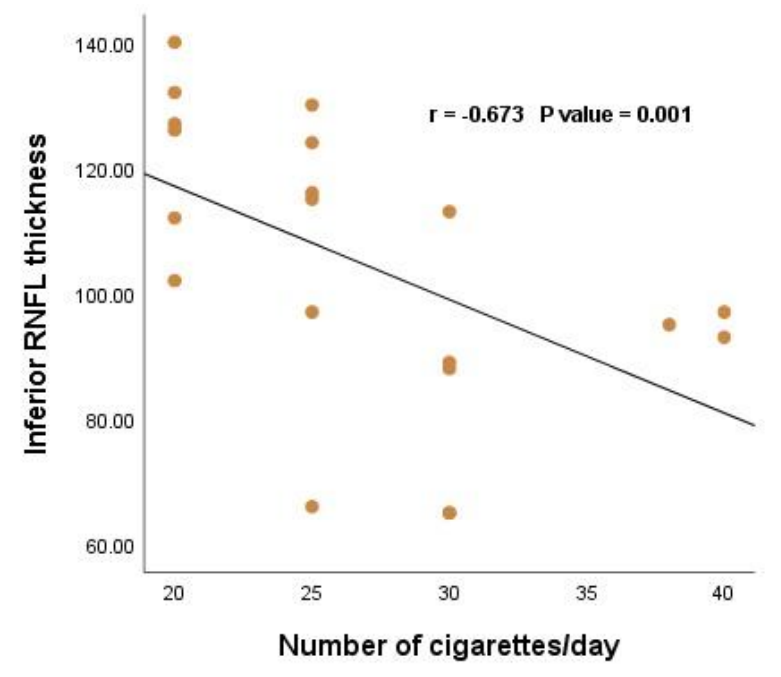

Figure 2: Correlation between inferior RNFL thickness and Number of cigarettes/day 


\section{Discussion:}

Optical coherence tomography (OCT) has revolutionized our ability to visualize structural abnormalities in the retina. Spectral-domain OCT (SD-OCT) provides significantly better image resolution, allowing detailed images of retinal morphologic features to be obtained [16].

Although it was stated that [17] the nasal, temporal, and central retinal thickness did not differ significantly between smokers and control groups, they proved that the mean RNFL was significantly thinner in the smokers group compared to that in the controls (inferior and superior quadrants of RNFL decreased in smoker group but temporal and nasal quadrants did not seem to be changed [18], which came in agreement with our reports.

RNFL thickness decreased in chronic heavy smokers, and the thinning is related to the amount of smoking rather than duration; and it could be due to direct neurotoxic effect on the optic nerve and reduced blood flow due to the vaso-constrictive effect of nicotine [19].
Our results came in accordance with most of previous investigators. There was no correlation between duration of smoking and RNFL thickness. From these results, we concluded that the amount of smoking is more effective than the duration of smoking in RNFL thinning.

\section{Conclusion}

This study reported that the thickness of retinal nerve fiber layer thickness decreases in chronic, healthy, heavy cigarette smokers, and this thinning is related to duration of smoking, but the ganglion cell layer thickness in heavy smokers was similar to those of the healthy individuals.

\section{References}

[1] J. E. Fielding, "Smoking: health effects and control," The New England Journal of Medicine, vol. 313, no. 8, pp. 491-498, 1985.

[2] C. L. Sarin, J. C. Austin, and W. O. Nickel, "Effects of smoking on digital blood flow velocity," Jama, vol. 229, no. 10, pp. 1327-1328, 1974.

[3] K. M. Bertram, C. J. Baglole, R. P. Phipps, and R. T. Libby, "Molecular regulation of cigarette smoke induced-oxidative stress in human retinal pigment epithelial cells: implications for age-related macular degeneration," American Journal of Physiology. Cell 
Physiology, vol. 297, no. 5, pp. C1200 - C1210, 2009.

[4] E. O. Ojofeitimi, D. A. Adelekan, A. Adeoye, T. G. Ogungbe, A. O. Imoru, and E. C. Oduah, "Dietary and lifestyle patterns in the aetiology of cataracts in Nigerian patients," Nutrition and Health, vol. 13, no. 2, pp. 61-68, 1999.

[5] S. Velilla, J. J. García-Medina, A. García-Layana et al., "Smoking and agerelatedmaculardegeneration:reviewandupdate," Journal of Ophthalmology, vol. 2013, Article ID 895147, p. 11, 2013.

[6] L. Xu, Q. S.Yo, W. Liu, and J. B. Jonas, "Smoking and retinal vein occlusions. the Beijing Eye Study," Graefe's Archive for Clinical and Experimental Ophthalmology, vol. 248, no. 7, pp. 1045-1046, 2010.

[7] Y. Solberg, M. Rosner, and M. Belkin, "The association between cigarette smoking and ocular diseases," Survey of Ophthalmology, vol. 42, no. 6, pp. 535-547, 1998.

[8] W. M. Wiersinga, "Smoking and thyroid," Clinical Endocrinology, vol. 79, no.2, pp. 145-151, 2013.

[9] R. Edwards, J. Thornton, R. Ajit, R. A. Harrison, and S. P. Kelly, "Cigarette smoking and primary open angle glaucoma: a systematic review," Journal of Glaucoma, vol. 17, no. 7, pp. 558-566, 2008.

[10] A. Grzybowski and G. E. Holder, "Tobacco optic neuropathy (TON) - the historical and present concept of the disease," Acta Ophthalmologica, vol. 89, no. 5, pp. 495-499, 2011.
[11] I. F. Hepsen and C. Evereklioglu, "Defective visual field tests in chronic heavy smokers," Acta Ophthalmologica Scandinavica, vol. 79, no. 1, pp. 53-56, 2001.

[12] J. C. Mwanza, D. L. Budenz, D. G. Godfrey, R. Carter, and A. S. Crandall, "Diagnostic performance of optical coherence tomography ganglion cell inner plexiform layer thickness measurements in early glaucoma," Ophthalmology, vol. 119, no. 6, pp. 1151-1158, 2012.

[13] F. Costello, W. Hodge, and Y. I. Pan, "Exploring the association between retinal nerve fiber layer thickness and initial magnetic resonance imaging findings in patients with acute optic neuritis," Multiple Sclerosis International, vol. 2011, Article ID 289785, p. 6, 2011.

[14] Z. Shi, Y. Wu, M. Wang et al., "Greater attenuation of retinal

nerve fiber layer thickness in Alzheimer's disease patients," Journal of Alzheimer's Disease, vol. 40, no. 2, pp. 277-283, 2014.

[15] Konstantinidis L \& Guex-Crosier Y: Hypertension and the eye, Current Opinion in Ophthalmology 2016; 27(6):514-521.

[16] Suzuki M, Minamoto A, Yamane K, Uka J, Aoki S \& Mishima HK: Malignant hypertensive retinopathy studied with optical coherence tomography. Retina 2005; 25:383-384.

[17] M. S. Dervişoğulları, Y. Totan, A. Tenlik, and A. Yuce, "Effects of cigarette smoking on choroidal and retinal thickness and ocular pulse amplitude," Cutaneous and Ocular Toxicology, vol. 34, no. 3, pp. 217-221, 2015. 
[18] M. S. Dervişoğulları, Y. Totan, A. Tenlik, A. Yüce, and E. Güler, "Effect of smoking on retina nerve fiber layer and ganglion cell-inner plexiform layer complex," Cutaneous and Ocular Toxicology, vol. 34, no. 4, pp. 282-285, 2015.
[19] M. Langhans, G. Michelson, and M. J. Groh, "Effect of breathing $100 \%$ oxygen on retinal and optic nerve head capillary blood flow in smokers and non-smokers," The British Journal of Ophthalmology, vol. 181, no. 5, pp. 365-369, 1997.

To cite this article: Mohamed A El-shayeb, Mohammed T Hegazy, Ashraf H El-Habbak, Marwa A Tabl. Evaluation the Effect of Smoking on the Thickness of Central Retinal Nerve Fiber and Ganglion Cell Layer Using OCT. BMFJ 2022;39:117-125. (ophthalmology):DOI: 10.21608/bmfi.2021.18521.1141 